\title{
Composite Strain Hardening Properties of High Performance Hybrid Fibre Reinforced Concrete
}

\author{
Vikram Jothi Jayakumar and Sivakumar Anandan \\ Structural Engineering Division, VIT University, Vellore 632014, India \\ Correspondence should be addressed to Sivakumar Anandan; sivakumara@vit.ac.in
}

Received 28 February 2014; Accepted 18 June 2014; Published 13 July 2014

Academic Editor: Andreas Kappos

Copyright ( 2014 V. Jothi Jayakumar and S. Anandan. This is an open access article distributed under the Creative Commons Attribution License, which permits unrestricted use, distribution, and reproduction in any medium, provided the original work is properly cited.

\begin{abstract}
Hybrid fibres addition in concrete proved to be a promising method to improve the composite mechanical properties of the cementitious system. Fibre combinations involving different fibre lengths and moduli were added in high strength slag based concrete to evaluate the strain hardening properties. Influence of hybrid fibres consisting of steel and polypropylene fibres added in slag based cementitious system (50\% CRL) was explored. Effects of hybrid fibre addition at optimum volume fraction of $2 \%$ of steel fibres and $0.5 \%$ of PP fibres (long and short steel fibre combinations) were observed in improving the postcrack strength properties of concrete. Test results also indicated that the hybrid steel fibre additions in slag based concrete consisting of short steel and polypropylene (PP) fibres exhibited a the highest compressive strength of $48.56 \mathrm{MPa}$. Comparative analysis on the performance of monofibre concrete consisting of steel and PP fibres had shown lower residual strength compared to hybrid fibre combinations. Hybrid fibres consisting of long steel-PP fibres potentially improved the absolute and residual toughness properties of concrete composite up to a maximum of $94.38 \%$ compared to monofibre concrete. In addition, the relative performance levels of different hybrid fibres in improving the matrix strain hardening, postcrack toughness, and residual strength capacity of slag based concretes were evaluated systematically.
\end{abstract}

\section{Introduction}

Fibre addition to concrete improves the tensile performance due to secondary reinforcing mechanism provided in the matrix. There had been considerable advancements on the efficient use of fibres in tailoring postcrack performance. Different types of fibres, either low modulus or high modulus, were added to increase the crack resistance properties [1-3]. In addition the metallic fibres such as steel and nonmetallic fibres such as polyester, polyethylene, polyvinyl acetate, and polypropylene were found to smoothen the postelastic strain softening properties of concrete. The load deformation characteristics of fibre incorporated concrete are known to provide the required strain hardening and strain softening properties when subjected to loading $[4,5]$. Studies indicated that the appropriate selection of fibre types and fibre modulus can result in the improvement of mechanical properties of brittle concrete. The proper selection of mix constituents and the effect of fine to coarse aggregate ratio have significant influence on the fibre reinforcing efficiency [6-8]. It is understood from the studies that the matrix reinforcing efficiency is dependent on selecting the optimal volume fraction of fibres. This can result in lower fibre spacing and can effectively strengthen the matrix resulting in the delay for matrix cracking. The origination and propagation of microcracks can be better controlled with the presence of bridging mechanism using fibres $[9,10]$. This can result in subsequent reduction on the crack width formation during continuous drawdown of the load deformation process. In another study conducted on hybrid steel-PP fibres the toughness properties were found to be dependent on degree of cracking [11]. High modulus fibres control the residual strength after failure and low modulus fibres control the ductility of the composite leading to large deformation. Optimal volume fractions of steel fibres at $2 \% V_{f}$ and polymeric fibres up to $0.3 \% V_{f}$ exhibited characteristic improvements on the strain hardening properties [12]. In another study it was indicated that the different hybrid fibre combinations consisting of steel 
TABle 1: Properties of different fibres and volume fraction of fibre to mortar.

\begin{tabular}{lcccc}
\hline Fibre type & Diameter $(\mathrm{mm})$ & Length $(\mathrm{mm})$ & Tensile strength $(\mathrm{MPa})$ \\
\hline Hooked steel & 0.50 & 60 (long) & 35 (short) & 1700 \\
Crimped polypropylene & 0.587 & 47 (long) & 23.5 (short) & 450 \\
\hline
\end{tabular}

TABLE 2: Final mixture proportions reached based on the initial studies.

\begin{tabular}{lcccccc}
\hline $\begin{array}{l}\text { Coarse aggregate } \\
(\mathrm{CA})-\text { mortar }(\mathrm{M}) \%\end{array}$ & \multicolumn{2}{c}{$\begin{array}{c}\text { Binder }(\mathrm{B}) \mathrm{kg} / \mathrm{m}^{3} \\
\text { Cement }\end{array}$} & $\begin{array}{c}\text { Fine aggregate } \\
\text { Slag }\end{array}$ & $\begin{array}{c}\text { Coarse aggregate } \\
(\mathrm{FA}) \mathrm{kg} / \mathrm{m}^{3}\end{array}$ & $\begin{array}{c}\text { Water/binder } \mathrm{kg} / \mathrm{m}^{3} \\
\text { ratio }\end{array}$ & $\begin{array}{c}\text { Chemical admixture } \\
(\mathrm{HRWR})\end{array}$ \\
\hline CA 60\%-M 40\% & 225 & 225 & 705.26 & 1258.34 & 0.3 & $1 \%$ \\
\hline
\end{tabular}

and polymeric fibres (polyester, polypropylene, and glass) had shown considerable improvements on the mechanical properties as well as reduction in shrinkage of concrete [13].

Performance of fibre addition is known to be superior in high strength matrix rather than ductile matrix due to real benefits of fibre straining being experienced at large deformation [14]. In another study it is indicated that the fibre addition can delay the initial crack formation upon stress [15]. This provides a major application for prefabricated light weight concrete elements which undergoes handling initial stress. Presence of fibres provides adequate matrix strengthening and can provide rigidity towards microcrack formation. It is understood from the literature that hybrid fibre addition in concrete can potentially improve the hardening mechanical properties. Further investigations are needed to explore the toughness characteristics of the composite incorporating the different hybrid fibre combinations. The effects of steel-PP fibres on the strain hardening and strain softening properties of the concrete need special attention. Also, the effect of fibre addition on the matrix strengthening and its improvements in slag based cementitious system requires more experimental validation.

1.1. Research Significance. The present study emphasizes the evaluation of mechanical properties of high performance slag based concrete incorporating fibre combinations. Steel and polypropylene (PP) fibres were added at different volume fractions and the postcrack performance was measured using load- deformation characteristics. Flexural evaluations were measured using load and deformation controlled methods by using Japanese yoke setup and true deflection was calculated. A special concrete mixture design method was carried out to select the matrix constituents for effective fibre performance.

\section{Materials Used}

\subsection{Binder Materials Used and Their Composition}

(i) Cement-ordinary Portland cement of 53 grade was used in the present study which had a specific gravity of 3.21 .

(ii) Binder-ground granulated blast-furnace slag (GGBS) obtained from industrial waste was used as

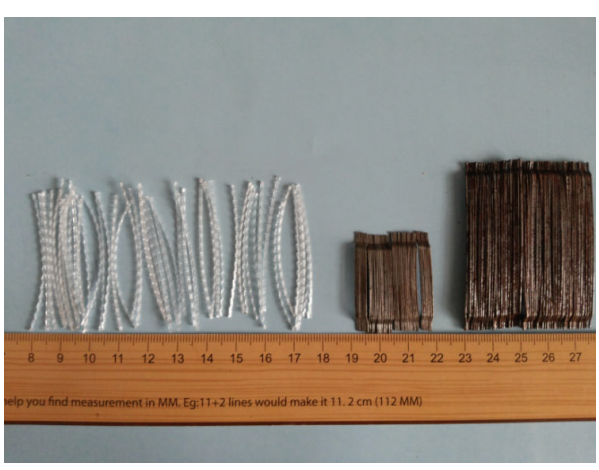

FIGURE 1: Snapshot of polypropylene and hooked steel fibres used in the study.

supplementary cementitious material and the silica content was $32.3 \%$ with alumina around $10.48 \%$.

(iii) Aggregates fillers-river sand passing through $4.75 \mathrm{~mm}$ and coarse aggregate passing through $20 \mathrm{~mm}$ and $12.5 \mathrm{~mm}$ were taken at $60: 40$ ratio.

(iv) Chemical admixture-to improve the workability of fresh concrete mixtures, a polycarboxylate ether based superplasticizer condensate was used as high range water reducing admixture (HRWR) which had a specific gravity of 1.18 .

(v) Fibres-a low modulus polypropylene and high modulus steel fibres (as shown in Figure 1) were added in concrete mixes and the properties are given in Table 1.

2.2. Concrete Mixture Proportions. Concrete mixtures were designed based on the minimum cement content using aggregate packing methodology. Target strength of M40 grade of controlled concrete was achieved using the granular packing concept. Various constituents such as aggregate fillers and binder were determined based on packing volume of concrete. Maximum packing density evaluation of aggregates provided the minimum quantity of binder volume required. The final mixture and detailed proportions of various concrete mixes reached are given in Tables 2 and 3. Different hybrid fibre combinations consisting of long and 
TABLE 3: Detailed mixture proportions for various concretes with coarse aggregate $60 \%$ and mortar $40 \%$ and different fibre dosages.

\begin{tabular}{|c|c|c|c|c|c|c|c|c|c|}
\hline \multirow{2}{*}{ Mix ID } & \multirow{2}{*}{$\begin{array}{c}\text { Fibre } \\
\text { combination }\end{array}$} & \multirow{2}{*}{ Fibre types } & \multirow{2}{*}{$\begin{array}{c}\text { Coarse aggregate } \\
\mathrm{kg} / \mathrm{m}^{3}\end{array}$} & \multirow{2}{*}{$\begin{array}{l}\text { Fine aggregate } \\
\qquad \mathrm{kg} / \mathrm{m}^{3}\end{array}$} & \multicolumn{2}{|c|}{ Binder $\mathrm{kg} / \mathrm{m}^{3}$} & \multirow{2}{*}{$\mathrm{w} / \mathrm{b}$ ratio } & \multicolumn{2}{|c|}{ Fibre dosage $\%$} \\
\hline & & & & & Cement & Slag & & $\mathrm{PP}$ & SF \\
\hline PP1 & \multirow{4}{*}{ Mono } & PP $47 \mathrm{~mm}$ & 1258.34 & 705.26 & 225 & 225 & 0.3 & 1 & - \\
\hline PP2 & & PP $23.5 \mathrm{~mm}$ & 1258.34 & 705.26 & 225 & 225 & 0.3 & 1 & - \\
\hline SF1 & & SF $60 \mathrm{~mm}$ & 1258.34 & 705.26 & 225 & 225 & 0.3 & - & 4 \\
\hline SF2 & & SF $35 \mathrm{~mm}$ & 1258.34 & 705.26 & 225 & 225 & 0.3 & - & 4 \\
\hline HPP3 & \multirow{6}{*}{ Hybrid } & PP 47 mm-PP $23.5 \mathrm{~mm}$ & 1258.34 & 705.26 & 225 & 225 & 0.3 & 1 & - \\
\hline HSF3 & & SF $60 \mathrm{~mm}-\mathrm{SF} 35 \mathrm{~mm}$ & 1258.34 & 705.26 & 225 & 225 & 0.3 & - & 4 \\
\hline HYF1 & & PP $47 \mathrm{~mm}-\mathrm{SF} 60 \mathrm{~mm}$ & 1258.34 & 705.26 & 225 & 225 & 0.3 & 0.5 & 2 \\
\hline HYF2 & & PP $23.5 \mathrm{~mm}$-SF $60 \mathrm{~mm}$ & 1258.34 & 705.26 & 225 & 225 & 0.3 & 0.5 & 2 \\
\hline HYF3 & & PP 47 mm-SF 35 mm & 1258.34 & 705.26 & 225 & 225 & 0.3 & 0.5 & 2 \\
\hline HYF4 & & PP $23.5 \mathrm{~mm}$-SF $35 \mathrm{~mm}$ & 1258.34 & 705.26 & 225 & 225 & 0.3 & 0.5 & 2 \\
\hline
\end{tabular}

Note: fibre dosages correspond to $\%$ of matrix volume fraction.

short fibre types of steel and polypropylene fibres were used in the present study.

2.3. Mixing, Casting, and Curing of Concrete Mixes. Concrete ingredients were initially mixed in a pan mixer of 60 litres capacity, wherein the dry mixing of ingredients was carried out for 3 minutes and then followed by the addition of fibre addition. Fibres are dispersed homogenously during addition in concrete mixer as the fibres were bunched together by water soluble glue. Steel fibre addition showed reduction in workability and was reinstated with the addition of high range water reducing (HRWR) admixture. Workability of concrete was affected at increased fibre dosage and showed a slump value in the range of 65 to $78 \mathrm{~mm}$; however with the superplasticizer addition the workability was improved to $90 \mathrm{~mm}$. Fresh concrete mixes were casted in different steel moulds required for testing different mechanical properties. Later after a day the casted specimens were remoulded and kept for required curing in a water tank.

2.4. Compressive Strength Test. Compressive strength properties were evaluated from concrete cube specimens (150 $\times 150 \mathrm{~mm} \times 150 \mathrm{~mm}$ ) in a compression testing machine of capacity $2000 \mathrm{kN}$. The rate of loading was kept constant at $2.5 \mathrm{KN} / \mathrm{sec}$ throughout the entire testing process.

2.5. Flexural Strength Test. Flexural test was carried out in a $100 \mathrm{KN}$ testing machine operating at a displacement rate of $0.5 \mathrm{~mm} / \mathrm{min}$ and the various properties such as ultimate flexural strength and load deformation properties were determined. True deflections at the centre of specimen were calculated using Japanese yoke arrangement [16] as shown in Figure 2 which facilitates the prevention of extraneous deflection at the ends. A three-point loading arrangement was used for conducting flexural test. Mechanical dial gauges were used to measure the load deformation values till failure of the concrete specimens. Further characteristic evaluation on the hybrid fibre and monofibre action in different concrete systems were analyzed.

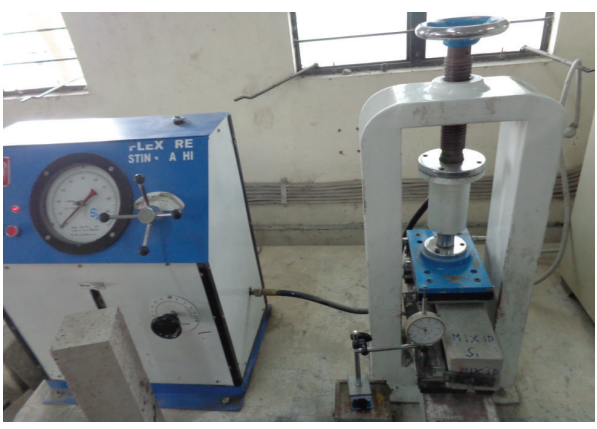

FiguRE 2: Test setup for flexural studies using three-point loading.

Based on the load-deflection plots drawn in Graph software V 4.2., various toughness calculations were calculated accurately as determined below.

(i) Absolute toughness represents the area under the entire load-deflection plot.

(ii) Postpeak toughness is calculated from the area between the ultimate load and failure load under load-deflection curve.

(iii) Residual toughness was measured from the area between the first drop in load after ultimate load till $3 \mathrm{~mm}$ deflection of the load-deflection curve.

(iv) Residual strength (\%) was calculated by dividing the residual load by the ultimate load.

\section{Experimental Test Results and Discussions}

3.1. Compressive Strength Properties. The compressive strength improvements in the case of different fibre reinforced concrete mixes are provided in Table 4 and shown in Figure 3. Test results indicated that fibre addition showed improved compressive strength $(48.56 \mathrm{MPa})$ in the case of hybrid fibre concrete mixes containing short steel and polypropylene fibre combinations. 
TABLE 4: Compressive and flexural properties of various mono- and hybrid fibre concretes.

\begin{tabular}{|c|c|c|c|c|c|c|c|c|c|c|}
\hline \multirow{3}{*}{$\begin{array}{l}\text { Mechanical } \\
\text { properties }\end{array}$} & \multicolumn{10}{|c|}{ Fibre types } \\
\hline & \multicolumn{4}{|c|}{ Monofibre types } & \multicolumn{6}{|c|}{ Hybrid fibre types } \\
\hline & $\begin{array}{c}\mathrm{PP} \\
47 \mathrm{~mm}\end{array}$ & $\begin{array}{c}\mathrm{PP} \\
23.5 \mathrm{~mm}\end{array}$ & $\begin{array}{c}\text { SF } \\
60 \mathrm{~mm}\end{array}$ & $\begin{array}{c}\mathrm{SF} \\
35 \mathrm{~mm}\end{array}$ & $\begin{array}{c}\mathrm{PP} 47 \mathrm{~mm} \\
\text { and PP } \\
23.5 \mathrm{~mm}\end{array}$ & $\begin{array}{c}\text { SF } 60 \mathrm{~mm} \\
\text { and SF } \\
35 \mathrm{~mm}\end{array}$ & $\begin{array}{l}\mathrm{PP} 47 \mathrm{~mm} \\
\text { and SF } \\
60 \mathrm{~mm}\end{array}$ & $\begin{array}{c}\text { PP } 23.5 \mathrm{~mm} \\
\text { and SF } \\
60 \mathrm{~mm}\end{array}$ & $\begin{array}{l}\mathrm{PP} 47 \mathrm{~mm} \\
\text { and SF } \\
35 \mathrm{~mm}\end{array}$ & $\begin{array}{c}\mathrm{PP} 23.5 \mathrm{~mm} \\
\text { and SF } \\
35 \mathrm{~mm}\end{array}$ \\
\hline $\begin{array}{l}\text { Compressive } \\
\text { strength (Mpa) }\end{array}$ & 35.74 & 28.5 & 34.25 & 47.8 & 31.3 & 46.21 & 38.03 & 40.1 & 43.25 & 48.56 \\
\hline $\begin{array}{l}\text { Flexural strength } \\
(\mathrm{Mpa})\end{array}$ & 5.67 & 5.95 & 5.41 & 6.08 & 5.75 & 7.78 & 6.81 & 6.63 & 6.78 & 7.52 \\
\hline $\begin{array}{l}\text { Residual strength } \\
(\mathrm{KN})\end{array}$ & 3.78 & 3.12 & 3.94 & 4.12 & 4.45 & 6.28 & 5.13 & 5.35 & 5.89 & 6.56 \\
\hline $\begin{array}{l}\text { Absolute } \\
\text { toughness }(\mathrm{N}-\mathrm{m})\end{array}$ & 62.45 & 13.2 & 112.4 & 51.5 & 25.6 & 104.2 & 121.4 & 80.12 & 110.4 & 98.5 \\
\hline $\begin{array}{l}\text { Postcrack } \\
\text { toughness (N-m) }\end{array}$ & 51.3 & 8.42 & 50.9 & 59.45 & 24.7 & 84.2 & 110.45 & 75.2 & 108.9 & 95.3 \\
\hline $\begin{array}{l}\text { Residual toughness } \\
(\mathrm{N}-\mathrm{m})\end{array}$ & 48.3 & 7.4 & 34.95 & 17.3 & 18.1 & 82.35 & 112.45 & 72.41 & 95.52 & 86.15 \\
\hline
\end{tabular}

Note. PP: polypropylene fibres; SF: steel fibres.

Test results denote average of 5 concrete samples for each concrete mix.

Standard deviation of compressive strength: $6.75 \mathrm{MPa}$; coefficient of variance: 0.172 .

Standard deviation of flexural strength: $3.12 \mathrm{MPa}$; coefficient of variance: 0.135 .

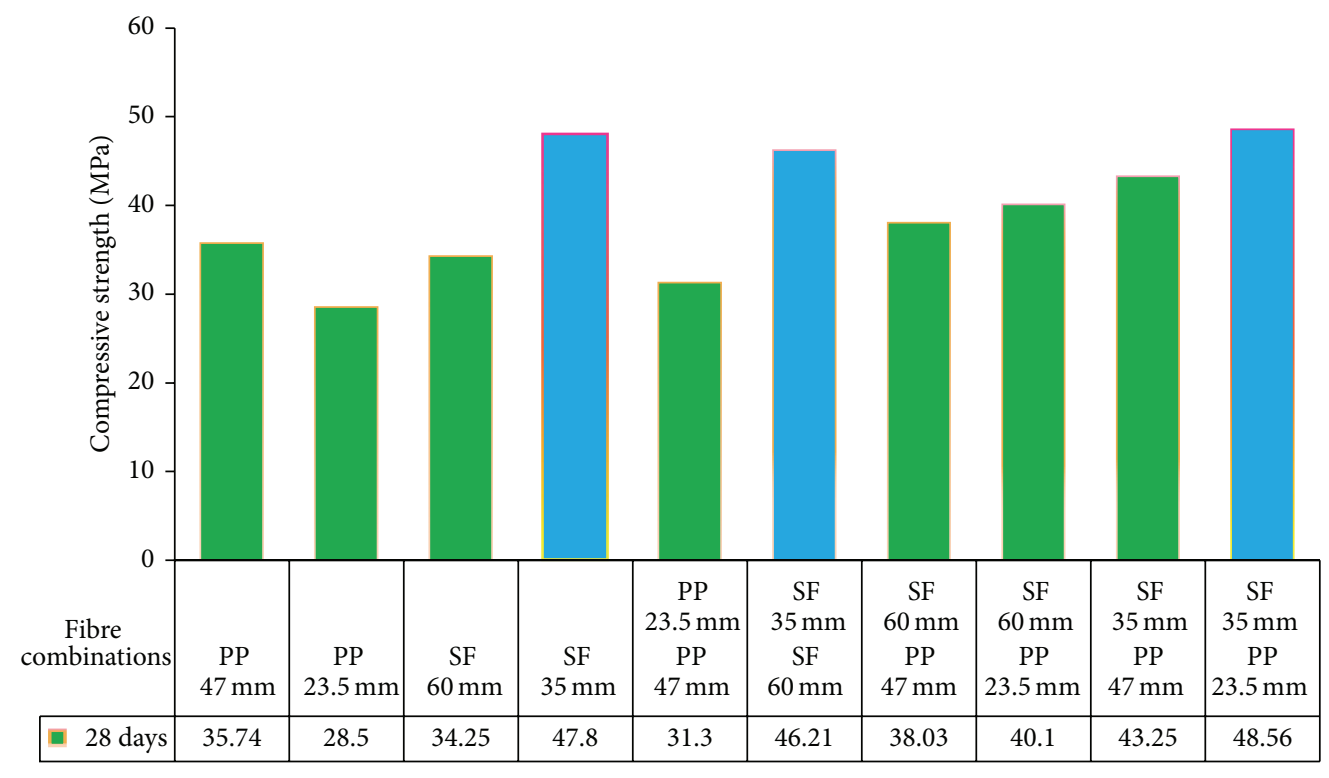

FIGURE 3: Compressive strength values for monofibre and hybrid fibre concrete mixes (28 days).

It can be also noted that monosteel fibre (short) concrete mix also exhibited the highest compressive strength of 47.8 Mpa. Similarly the hybrid fibre combinations containing short and long steel fibre combinations exhibited the highest compressive strength of $46.21 \mathrm{MPa}$. In the case of other monofibre concretes the strength increase was not anticipated compared to design concrete of M40 grade. Compressive properties were better improved in hybrid fibres with short fibre combinations due to large fibre availability and provided closer spacing of fibres. The right blends of high and low modulus fibres provide the required composite strength enhancement. Also, the shorter polypropylene fibres at higher volume fraction showed enhanced strength due to large fibre availability. This could be a result of low specific gravity and more fibres present in the matrix. The real bridging mechanism of fibres was not observed after examining the failed concrete specimens in which neither the fibre pullout nor fibre straining occurred in the fractured surface. The plane of fracture developed in compressive testing does not influence the tensile capacity of fibre from the matrix which possibly may not affect the ultimate strength capacity of the composite. However, the improvements in the compressive strength occurred as a result of effective matrix strengthening due to which delay in crack opening might possibly occur. 


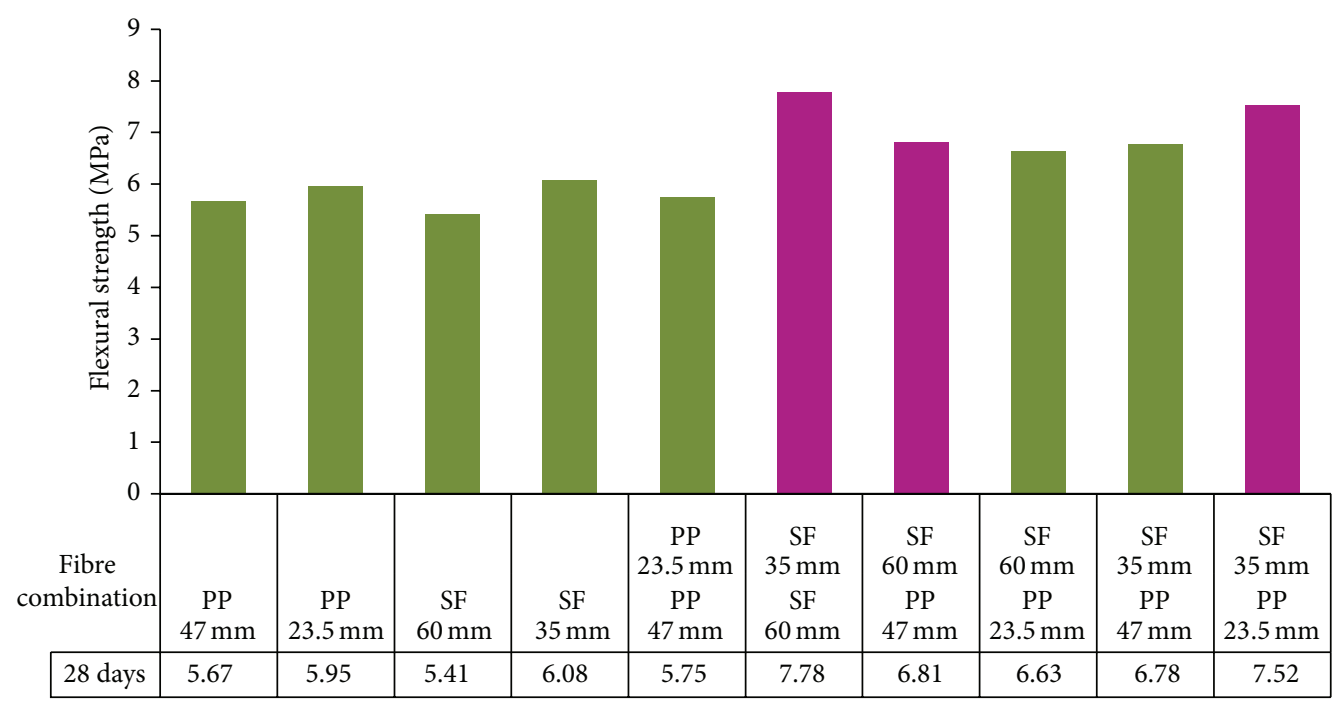

FIGURE 4: Flexural strength values for monofibre and hybrid fibre concrete mixes (28 days).

It can be concluded that compressive strength is a function of rigidity modulus of the composite occurring during shear strain along the plane of loading. The fibres influence the matrix strengthening and provide adequate shear resistance which can be justified as the reason for the increase in strength.

\subsection{Flexural Properties}

3.2.1. Ultimate Strength. Flexural testing of fibre composites provides adequate measure on the bending resistance of the material. Experimental trends showing the ultimate flexural capacity of various fibre concretes are shown in Figure 4. It can be noted that a maximum flexural strength of $7.78 \mathrm{MPa}$ and 7.52 MPa was noticed for hybrids consisting of steel fibres and short steel-PP combinations, respectively. Similarly the other hybrid combinations were also proved to be more effective in improving the ultimate flexural strength with a marginal decrease than the former hybrid types. Compared to hybrid fibre concretes, the addition of mono-steel nor PP fibres had shown an appreciable increase on the strength. This essentially showed the importance of fibre mechanism in the case of adding two fibre types. Among the different hybrids the short fibre combinations demonstrated higher load carrying capacity due to matrix strengthening. The large fibre availability and subsequent reduction in fibre spacing can possibly reduce the propensity for crack initiation.

The delay in crack origination and propagation can be identified as a possible mechanism which alters the flexural strength capacity of the composite. It is well conceived from the test results that the prepeak strain hardening properties are governed by the matrix cracking and stability of crack growth. The high strain hardening properties can possibly yield controlled deformation rate and can result in higher flexural strain capacity. It can be noted that the possible inclusions of hybrid fibres substantially improved the flexural stress capacity of the slag based high performance concrete.

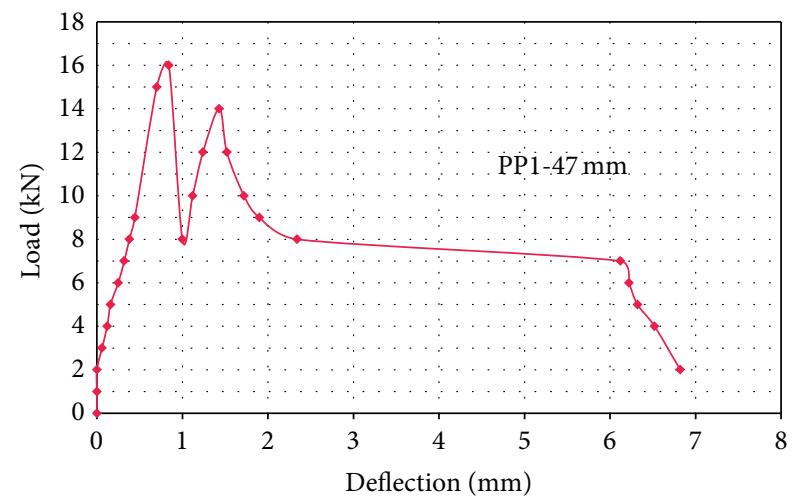

FIGURE 5: Load-deflection characteristics of long polypropylene fibre composite.

3.2.2. Load Deformation Characteristics. The characteristic mechanical behavior of the hybrid composite was noted in the load deformation properties when subjected to flexural loading. It can be noted from Figure 5 that the prepeak and postpeak curves for mono-PP fibre composite are well defined with a sudden drop in load after ultimate. However, further increase occurred with the gradual pseudostrain hardening noticed in the postpeak region and thereafter a gradual strain release was observed in the composite.

In the case of mono-short steel fibre composite the sudden drop in load was not noticed after peak; however, the gradual loss in stress occurred with complete failure that occurred due to pullout as seen in Figure 6. In the case of short steel fibre addition, the postpeak curve showed a gradual reduction in the stress carrying capacity without any visible signs of plastic deformation and can be noted in Figure 7. It indicates that, at large crack widths, the small fibres had not shown significant contribution to the crack bridging properties. 


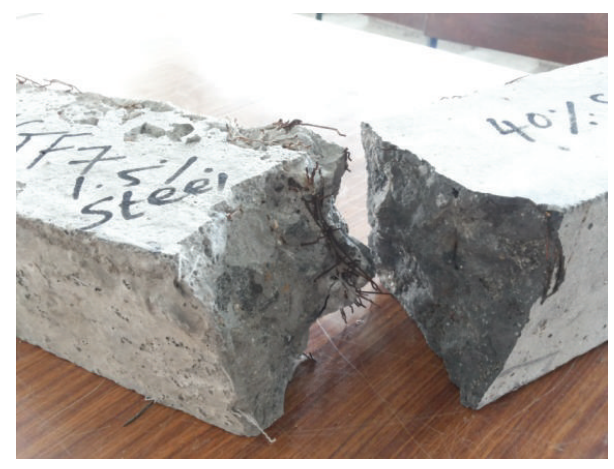

FIGURE 6: Fibre straining and pullout of failed hybrid composites.

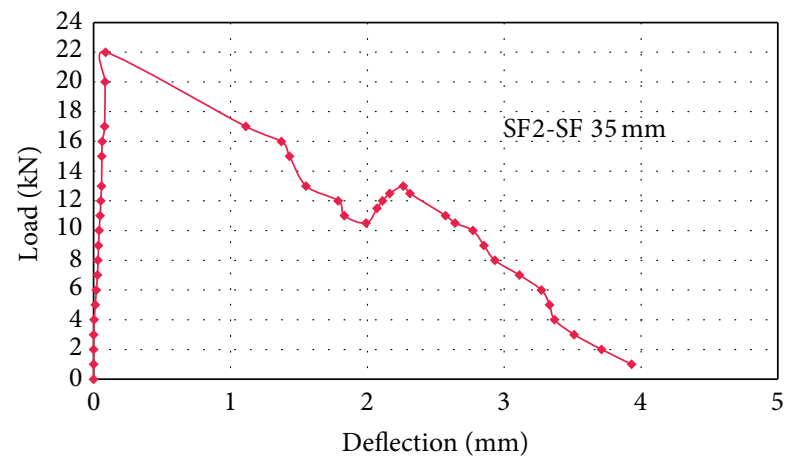

FIgURE 7: Load-deflection characteristics of mono-short steel fibre composite.

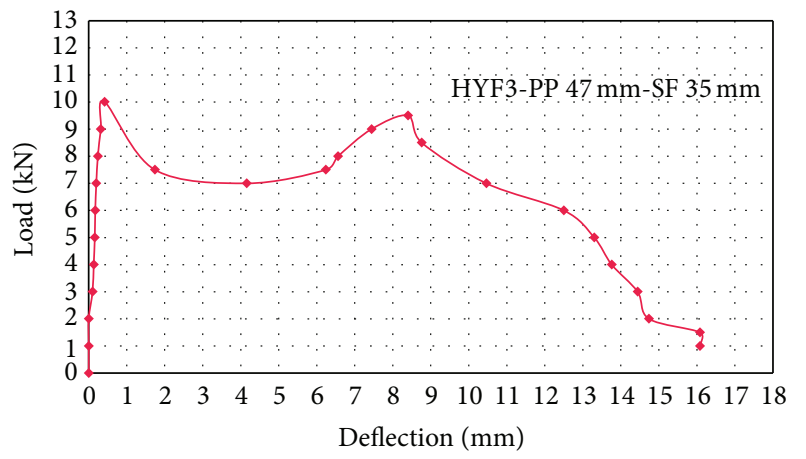

FIGURE 8: Load-deflection characteristics of short steel-long polypropylene fibre composite.

From Figure 8 of the load deformation curve, the hybrid fibres consisting of short steel-long PP fibre combination showed large deformation after peak with an initial sudden drop in load. However, the significance of adding two different fibre moduli was better observed with a pseudostrain hardening properties. This is indicated with plastic deformation occurring for large strain values which can be defined as the ductility of the composite. This was the characteristic property of hybrid concrete investigated in this study which demonstrates the synergistic interaction of fibre combinations in the postpeak region.

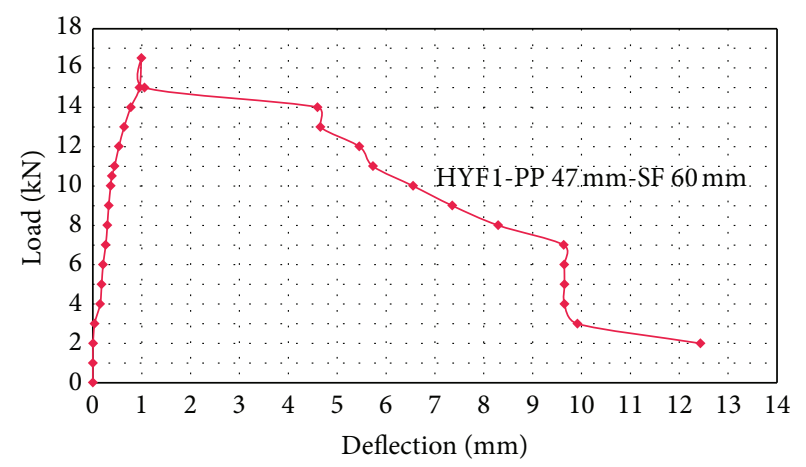

FIGURE 9: Load-deflection characteristics of hybrid long steelpolypropylene fibre composite.

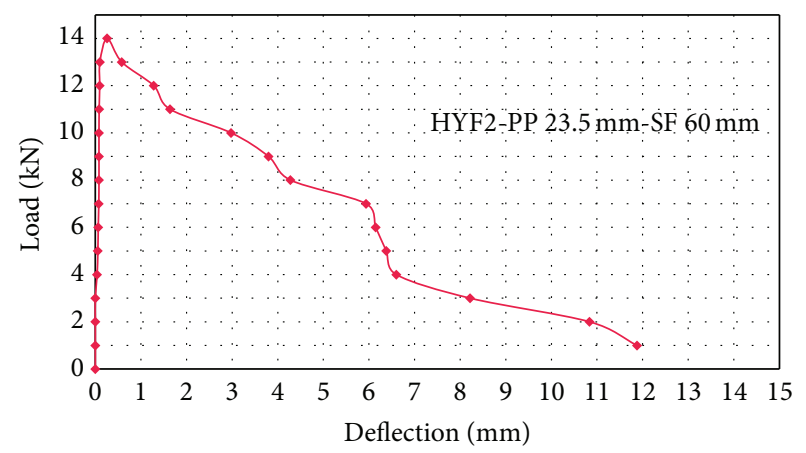

FIGURE 10: Load-deflection characteristics of hybrid long steel-short polypropylene fibre composite.

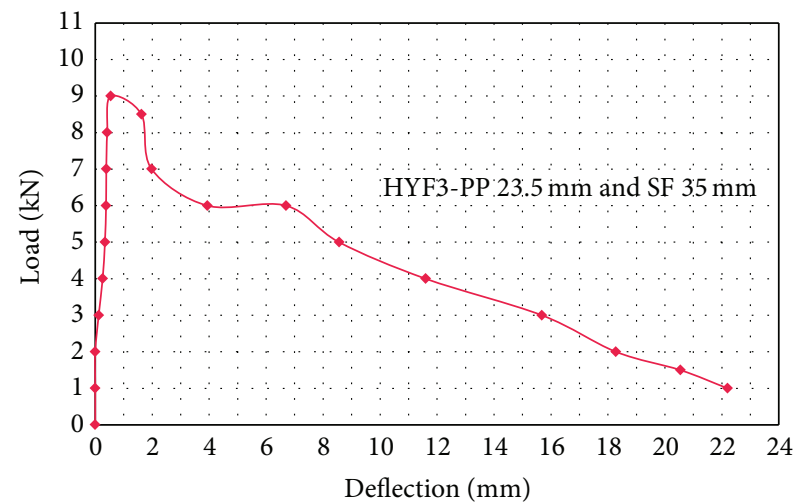

FIGURE 11: Load-deflection characteristics of hybrid short steelpolypropylene fibre composite.

Similarly the other hybrid combinations shown in Figures 9,10 , and 11 denoted the plastic strain hardening of the composite with gradual failure. However, it can be noted that the postpeak response of the composite is governed by the short steel fibres with large availability to bridge the unsteady crack growth. Also, the longer PP fibres provide adequate strain at failure of the composite resulting in improved ductility properties.

3.2.3. Residual Strength Capacity. The residual strength capacity denotes the load carrying capacity of the composite 


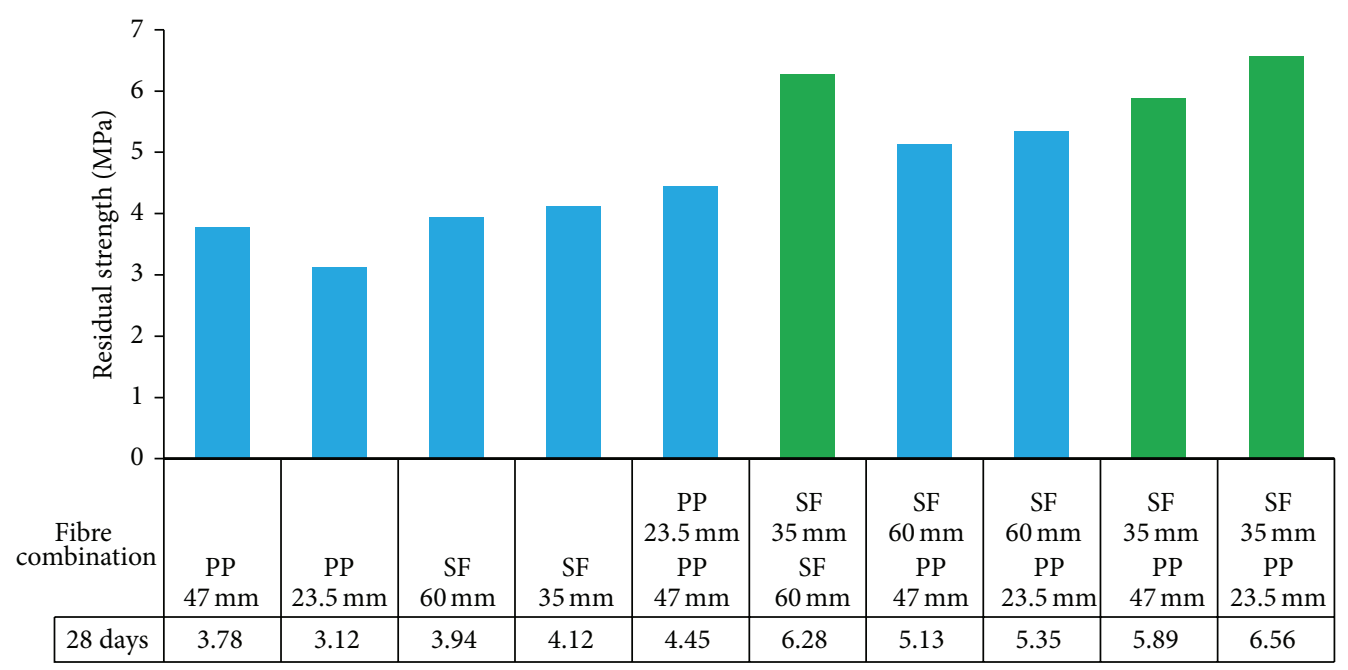

FIGURE 12: Residual strength capacity of hybrid short steel-polypropylene fibre composite.

after failure. It was clearly evident from the experimental results shown in Figure 12 that the maximum residual strength was noted in hybrid fibre concretes compared to monofibre concretes. Among the various hybrid fibre concretes, the maximum residual strength of $6.56 \mathrm{MPa}$ was measured in the case of short fibre types consisting of steelPP hybrid concretes. Also, a similar maximum residual strength of $6.28 \mathrm{MPa}$ was noted in the case of short and long steel fibre hybrid composites. The results indicate that the residual strength performance adequately indicates the relative level of stress capacity of the material after failure. The incorporation of hybrid fibre types essentially proved to demonstrate the flexural capacity of the matrix even after cracking. The steady crack bridging effects without sudden energy dissipation can be adequately controlled by high and low modulus fibre addition in concrete.

3.3. Absolute Toughness. The energy absorption capacity of the concrete composite is defined as the toughness and measured from the area under load deformation curve and provided in Figure 13. It can be noted that compared to monofibre additions, hybrid fibre concretes exhibited higher absolute toughness. Among the different hybrid fibre concretes tested, the hybrid concretes containing long fibre steelPP fibre combinations showed the highest toughness value of $121.4 \mathrm{~N}-\mathrm{m}$. A similar toughness was observed in the case of long monosteel fibre concrete and apparently showed a synergy existing when long fibre hybrids were incorporated in concrete. Most notably the longer fibres proved to be efficient in bridging macrocracks and further the straining of fibres was anticipated. This could possibly be the mechanism resulting in large area under the load deformation curve and significantly yielding a higher toughness value.

In general it can be justified that the fibre matrix interaction is better enhanced in the case of hybrid fibre combinations containing long fibres of low and high modulus types which showed synergistic interaction in the high strength matrix. It can be stated from the fundamental mechanics

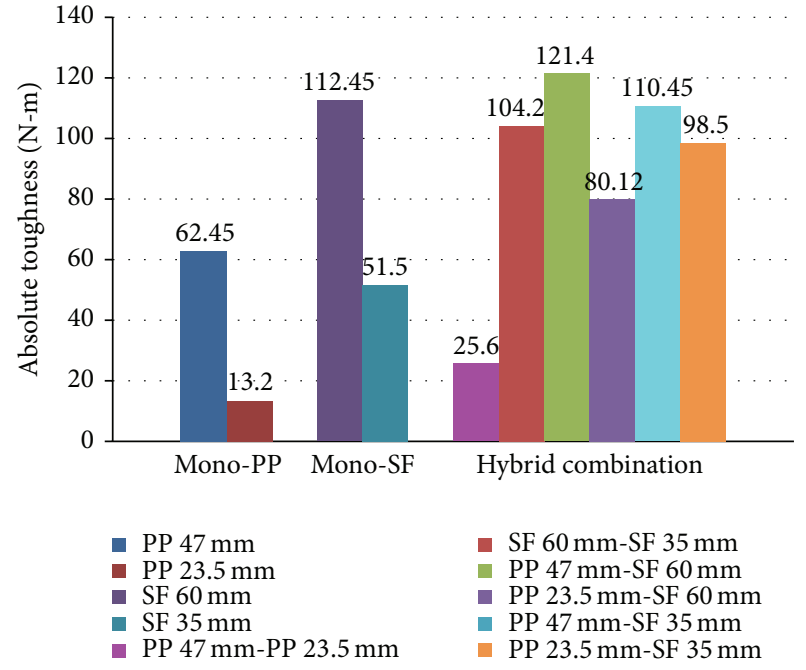

FIGURE 13: Absolute toughness of various fibre concretes measured under the load-deflection curve.

of hybrid action that the fibre matrix interface is influenced by the longer length of fibres due to which there is a corresponding crack bridging stress. Also, the crack bridging stress is a function of number of fibres available at the crack front and dependent on the fibre modulus. In the case of hybrid fibres compared to longer lengths and high specific gravity fibres generally the number of fibres available will be more for a small length and low specific gravity. It can be also noted that the fibre reinforcement index which is a function of number of fibres available for a given concrete area is more for low modulus polypropylene fibres compared to steel fibres. This possibly reveals that, upon crack propagation, the stress balancing occurs at $95 \%$ of the ultimate load due to matrix cracking and further instability after peak load resulting in large crack width could not possibly be bridged by low modulus PP fibres. This is eventually seen as sudden drop in load in the case of PP fibre substitution and can be 


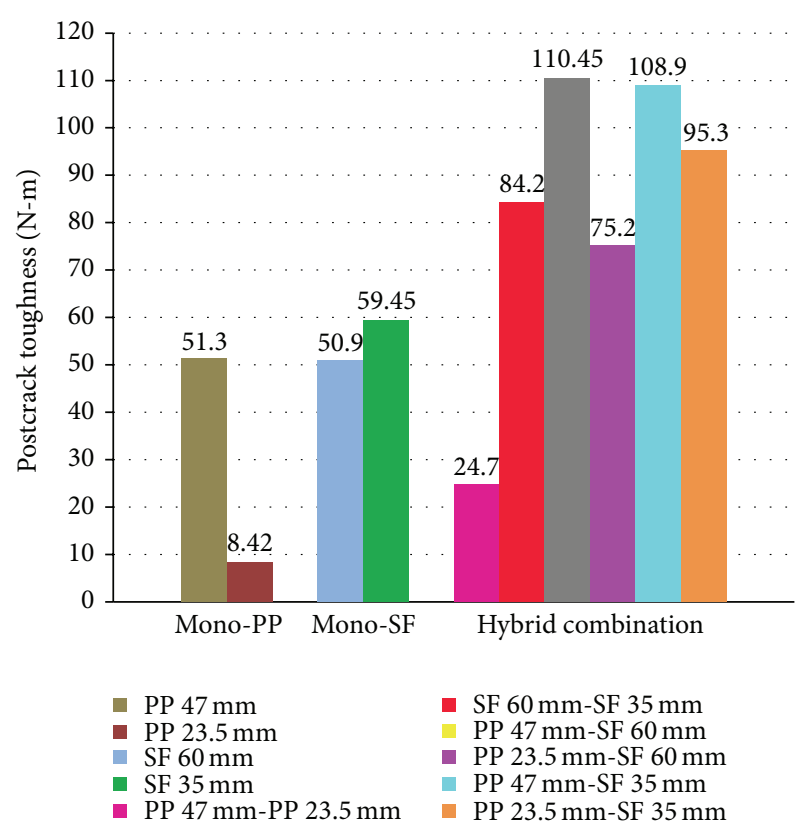

Figure 14: Postcrack toughness of various fibre concretes measured under the load-deflection curve.

also seen to improve with high volume fraction of PP fibres in the matrix.

3.4. Postcrack/Postultimate Toughness (PCT). The toughness capacity of the material after cracking is defined as the postcrack energy absorbing capacity of the material and the values for various hybrid concretes are provided in Figure 14. Compared to monofibre concretes the hybrid fibre concretes showed a corresponding increase on the postcrack resistance of the material. Among the different hybrid concretes, long fibre combinations of steel-PP fibres showed higher postcrack toughness value around $110.45 \mathrm{~N}-\mathrm{m}$ and a similar increase up to $108.9 \mathrm{~N}-\mathrm{m}$ was anticipated in the case of PP fibre combinations. In the case of short fibre combinations of steelPP fibres the maximum PCT was measured around 95.3 N-m. The results proved to be demonstrating the hybrid fibre reinforcing efficiency even after cracking and revealed that possible synergy can be anticipated when fibre combinations are used for improving the high strength concrete matrix.

3.5. Residual Toughness (RT). Toughness measured at the onset of first drop in load is used to define the energy absorbing capacity of the composite. The test result of the various hybrid composites is given in Figure 15 and possibly gives an estimation of the flexural capacity of the material even after failure. The hybrids consisting of long steel-PP fibre combinations showed the highest residual toughness and indicate a possible synergy of the composite.

\section{Conclusions}

From the experimental studies conducted, the following inferences related to hybrid fibre mechanism in a high strength slag based concrete are drawn.

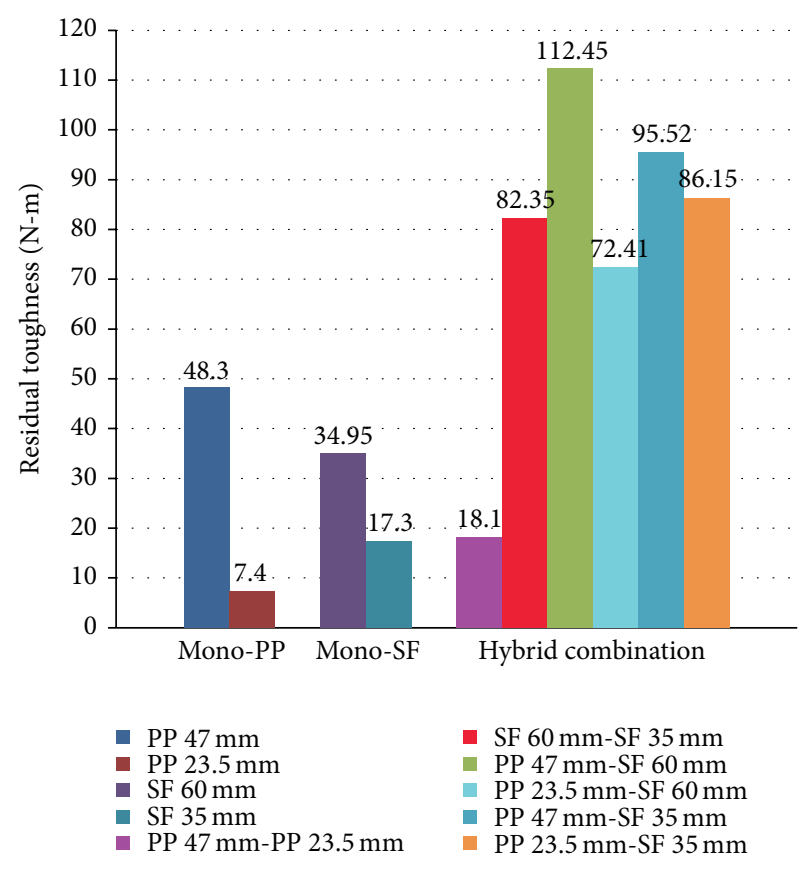

FIGURE 15: Residual toughness of various fibre concretes measured under the load-deflection curve.

(i) Fibre addition consisting of polypropylene and steel showed considerable mechanical strength improvements with higher strain hardening properties of slag based concrete.

(ii) Compressive properties were favorably improved with the inclusion of hybrid fibres consisting of steel-PP and a maximum compressive strength was recorded up to $48.56 \mathrm{MPa}$.

(iii) Flexural strength enhancements were better observed in the case of steel-PP hybrid fibre concretes and a maximum flexural strength of $7.78 \mathrm{MPa}$ and $7.52 \mathrm{MPa}$ was noticed for hybrids consisting of long and short steel fibres and short steel-PP combinations, respectively.

(iv) Similarly the other hybrid combinations also proved to be effective in improving the ultimate flexural strength with a marginal decrease in other hybrid types. This essentially showed the importance of fibre mechanism in the case of adding two fibre types. Among the different hybrids, the short fibre combinations demonstrated higher load carrying capacity due to matrix strengthening.

(v) Toughness of the composite was found to be better enhanced in hybrid composite consisting of long fibre combinations than short fibre types. Crack bridging efficiency at higher load is effective in the case of longer fibres than shorter fibres.

(vi) Maximum absolute toughness (121.4 N-m) was noted in the case of long steel-PP fibre combinations and the postcrack toughness was found to be maximum in the case of long fibre combinations of steel-PP fibres. 
(vii) The residual strength and residual toughness of the composite were found to be maximum for hybrid short steel-PP fibre combinations in the concrete composite.

(viii) It can be concluded from the overall studies conducted that the inclusion of long hybrid fibre (steelPP) types had shown favorable prepeak and postpeak response of the slag based high performance concrete. Compared to monofibre addition, the real benefits in terms of improved mechanical performance can be anticipated in hybrid composites.

\section{Conflict of Interests}

The authors declare that there is no conflict of interests regarding the publication of this paper.

\section{References}

[1] N. Banthia and M. Sappakittipakorn, "Toughness enhancement in steel fiber reinforced concrete through fiber hybridization," Cement and Concrete Research, vol. 37, no. 9, pp. 1366-1372, 2007.

[2] W. Zheng, H. Li, and Y. Wang, "Compressive behaviour of hybrid fiber-reinforced reactive powder concrete after high temperature," Materials \& Design, vol. 41, pp. 403-409, 2012.

[3] D. A. S. Rambo, F. D. A. Silva, and R. D. T. Filho, "Mechanical behavior of hybrid steel-fiber self-consolidating concrete: materials and structural aspects," Materials and Design, vol. 54, pp. 32-42, 2014.

[4] S. P. Yap, C. H. Bu, U. Johnson Alengaram, K. Hung Mo, and M. Zamin Jumaat, "Flexural toughness characteristics of steelpolypropylene hybrid fibre-reinforced oil palm shell concrete," Materials and Design, vol. 57, pp. 652-659, 2014.

[5] H. S. Kim and Y. S. Shin, "Flexural behavior of reinforced concrete (RC) beams retrofitted with hybrid fiber reinforced polymers (FRPs) under sustaining loads," Composite Structures, vol. 93, no. 2, pp. 802-811, 2011.

[6] M. Sahmaran, A. Yurtseven, and I. Ozgur Yaman, "Workability of hybrid fiber reinforced self-compacting concrete," Building and Environment, vol. 40, no. 12, pp. 1672-1677, 2005.

[7] M. Hsie, C. Tu, and P. S. Song, "Mechanical properties of polypropylene hybrid fiber-reinforced concrete," Materials Science and Engineering A, vol. 494, no. 1-2, pp. 153-157, 2008.

[8] E. T. Dawood and M. Ramli, "Mechanical properties of high strength flowing concrete with hybrid fibers," Construction and Building Materials, vol. 28, no. 1, pp. 193-200, 2012.

[9] E. T. Dawood and M. Ramli, "Durability of high strength flowing concrete with hybrid fibres," Construction and Building Materials, vol. 35, pp. 521-530, 2012.

[10] A. Sivakumar and M. Santhanam, "A quantitative study on the plastic shrinkage cracking in high strength hybrid fibre reinforced concrete," Cement and Concrete Composites, vol. 29, no. 7, pp. 575-581, 2007.

[11] S. H. Park, D. J. Kim, G. S. Ryu, and K. T. Koh, “Tensile behavior of ultra high performance hybrid fiber reinforced concrete," Cement and Concrete Composites, vol. 34, no. 2, pp. 172-184, 2012.

[12] N. Banthia, F. Majdzadeh, J. Wu, and V. Bindiganavile, "Fiber synergy in hybrid fiber reinforced concrete (HYFRC) in flexure and direct shear," Cement \& Concrete Composites, vol. 48, pp. 91-97, 2014.

[13] E. T. Dawood and M. Ramli, "Contribution of hybrid fibers on the hybrid fibers on the properties of high strength concrete having high workability," in Proceedings of the 12th East AsiaPacific Conference on Structural Engineering and Construction (EASEC '11), vol. 14, pp. 814-820, Hong Kong, January 2011.

[14] S. P. Singh, "Fatigue strength of hybrid steel-polypropylene fibrous concrete beams in flexure," in Proceedings of the 12th East Asia-Pacific Conference on Structural Engineering and Construction (EASEC '12), vol. 14, pp. 2446-2452, January 2011.

[15] Z. You, X. Chen, and S. Dong, "Ductility and strength of hybrid fiber reinforced self-consolidating concrete beam with low reinforcement ratios," Systems Engineering Procedia, vol. 1, pp. 28-34, 2011, Proceedings of the International Conference on Risk and Engineering Management (REM).

[16] V. M. Sounthararajan and A. Sivakumar, "Toughness characterization of steel fibre reinforced concrete-a review on various international standards," Journal of Civil Engineering and Construction Technology, vol. 4, no. 3, pp. 65-69, 2013. 

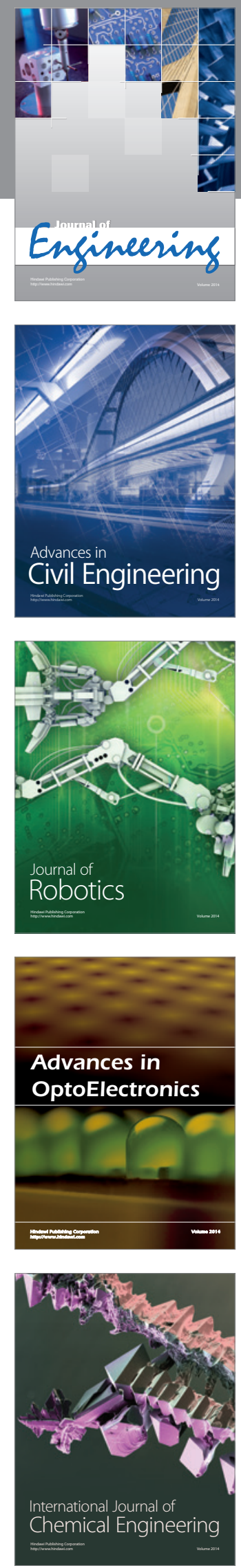

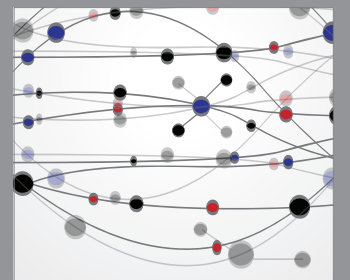

The Scientific World Journal
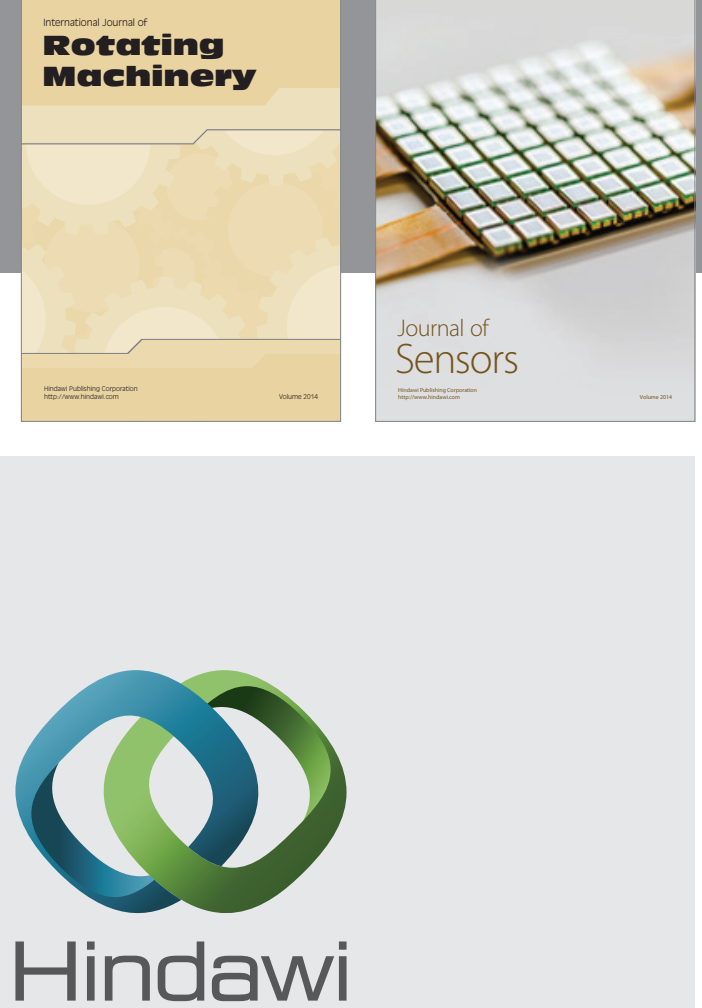

Submit your manuscripts at http://www.hindawi.com
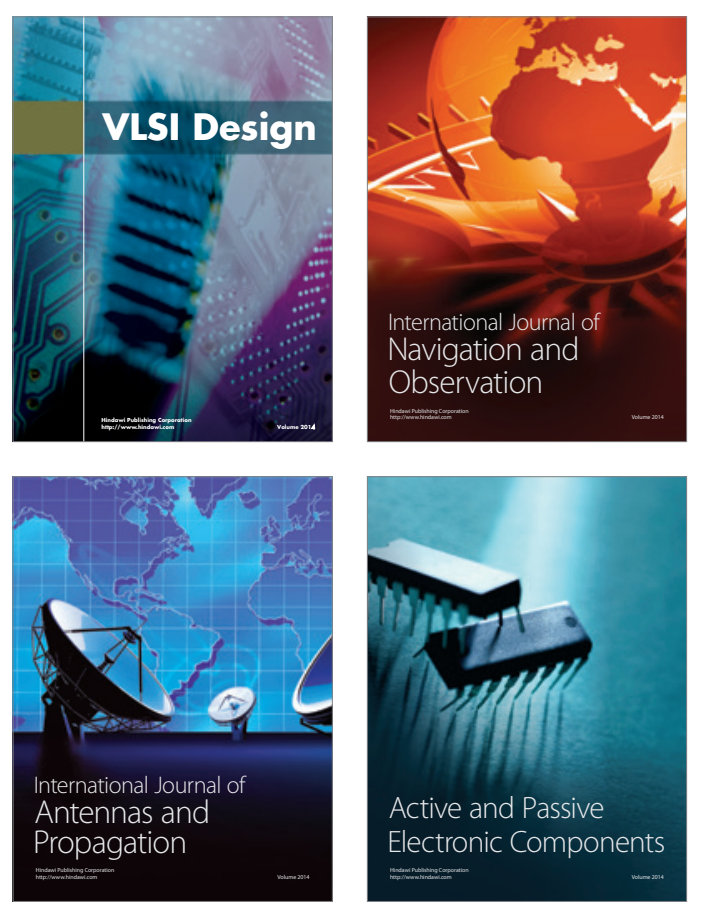
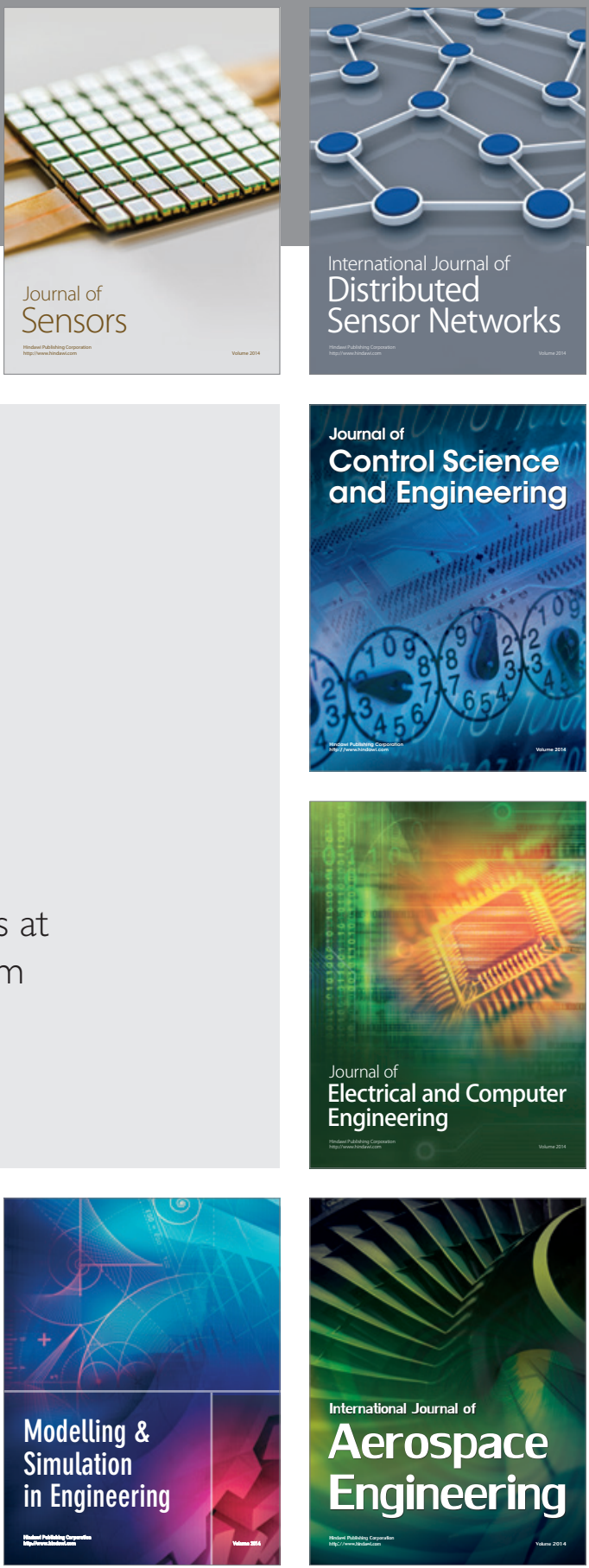

Journal of

Control Science

and Engineering
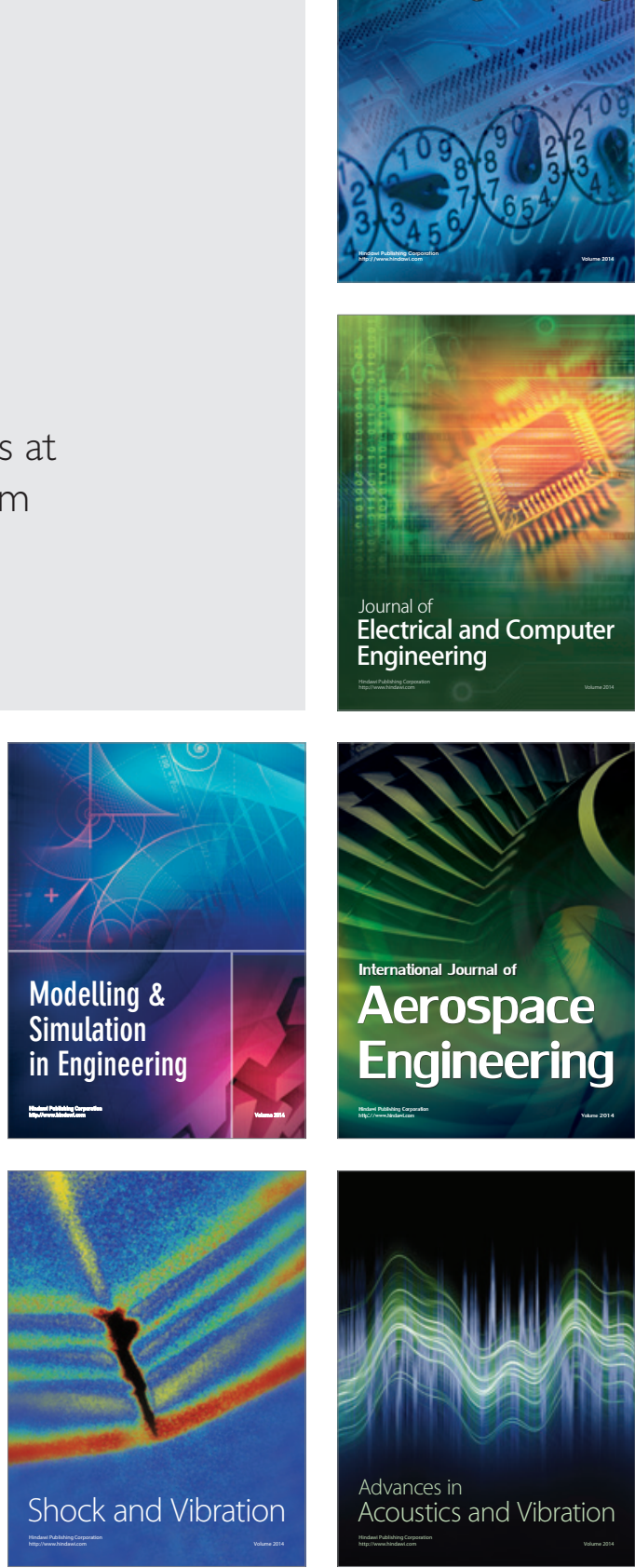